Department of Urology,

Stanford University School of

Medicine, 300 Pasteur Drive,

Stanford, CA 94305-5118, USA

${ }^{2}$ Department of Obstetrics and

Gynecology, Stanford University

School of Medicine, Stanford,

CA, USA

${ }^{3}$ Department of Pediatrics,

Stanford University School of

Medicine, Stanford, CA, USA

${ }^{4}$ Department of Biomedical

Data Science, Stanford

University School of Medicine,

Stanford, CA, USA

Correspondence to:

M L Eisenberg

eisenberg@stanford.edu

(or @drmeisenberg on Twitter)

Additional material is published

online only. To view please visit

the journal online.

Cite this as: $B M J$ 2018;363:k4372 http://dx.doi.org/10.1136/bmj.k4372

Accepted: 2 October 2018

\section{Association of paternal age with perinatal outcomes between 2007 and 2016 in the United States: population based cohort study}

\author{
Yash S Khandwala, ${ }^{1}$ Valerie L Baker, ${ }^{2}$ Gary M Shaw, ${ }^{3}$ David K Stevenson, ${ }^{3}$ Ying Lu, ${ }^{4}$ \\ Michael L Eisenberg ${ }^{1,2}$
}

\section{ABSTRACT}

OBJECTIVE

To evaluate the impact of advanced paternal age on maternal and perinatal outcomes in the United States. DESIGN

Retrospective, population based cohort study. SETTING

US.

\section{POPULATION}

40529905 documented live births between 2007 and 2016.

\section{MAIN OUTCOME MEASURES}

Primary perinatal outcomes were gestational age, birth weight, Apgar score at five minutes, admission to a neonatal intensive care unit, need for postpartum antibiotics, and seizures. Primary maternal outcomes were gestational diabetes and pre-eclampsia. Secondary outcome was the number of preventable perinatal events.

\section{RESULTS}

Higher paternal age was associated with an increased risk of premature birth, low birth weight, and low Apgar score. After adjustment for maternal age, infants born to fathers aged 45 years or older had $14 \%$ higher odds of premature birth (odds ratio 1.14 , $95 \%$ confidence interval 1.13 to 1.15 ), independent of gestational age, and $18 \%$ higher odds of seizures $(1.18,0.97$ to 1.44$)$ compared with infants of fathers aged 25 to 34 years. The odds of gestational diabetes was $34 \%$ higher $(1.34,1.29$ to 1.38$)$ in mothers with

\section{WHAT IS ALREADY KNOWN ON THIS TOPIC}

Mean paternal age in the United States has been increasing for the past 40 years Though extensive research has been done on the risks of infertility, gestational diabetes, pre-eclampsia, and cesarean delivery for older mothers, little is known about the influence of older fathers on birth outcomes

Recent studies have suggested that epigenetic changes in the sperm of older men might negatively affect placental and embryonic growth

\section{WHAT THIS STUDY ADDS}

Men aged 45 years or older had increased odds of fathering infants born premature, of low birth weight, and with a low Apgar score compared with their younger counterparts; the offspring of fathers older than 55 were also more likely to require assisted ventilation and admission to a neonatal intensive care unit The odds of gestational diabetes was also higher for pregnancies involving fathers older than 45 years

$13.2 \%$ of premature births and $14.5 \%$ of low birth weight infants born to older fathers were estimated to be prevented if all men elected to have children before age 45 years the oldest partners. $13.2 \%$ (95\% confidence interval $12.5 \%$ to $13.9 \%$ ) of premature births and $18.2 \%$ (17.5\% to $18.9 \%$ ) of gestational diabetes in births associated with older fathers were estimated to be attributable to advanced paternal age.

\section{CONCLUSIONS}

Advanced paternal age is associated with negative effects on both mothers and offspring. Given the relatively low prevalence of advanced paternal age in the US, population level impacts are currently modest. Nevertheless, as advanced paternal age has doubled in the US over the past generation, further investigation is warranted of the impact on birth outcomes and public health.

\section{Introduction}

The age at which couples have children in the United States continues to increase. ${ }^{12}$ The number of first births to women older than 35 years has risen by about $2 \%$ annually since the 1970 s, and the percentage of all births in the US to fathers aged more than 40 has doubled, to $9 \%$, over the same period. Though the effects of advanced maternal age on perinatal outcomes have been extensively studied, research on the impact of older fathers on the health of offspring has been limited mostly to the risk of congenital disease..$^{3-8}$

The high number of male germ cell divisions in aging fathers has been proposed to increase the risk of autism, genetic abnormalities, psychiatric morbidity, and neoplasia in offspring, but recent studies have also suggested a potential paternal effect on perinatal morbidity. ${ }^{6-14}$ One common explanation arises from the epigenetic changes that occur within spermatocytes; specifically modifications to histone and DNA methylation in spermatozoa of older men. These alterations occur in regions of the genome that are responsible for several diseases in offspring. ${ }^{15}$ Disruption of histone methylation in developing male germ cells might be a precursor to aberrant embryonic and placental development, with studies suggesting that paternal imprinting of aging could affect both fetal growth and maternal health during pregnancy. ${ }^{1617}$

Utilizing birth registries, several groups have attempted to characterize the risk of advanced paternal age on adverse birth events such as preterm birth, low birth weight, and pre-eclampsia. ${ }^{18}$ Findings remain inconclusive, however, owing to insufficient sample sizes, short study periods, and difficulty obtaining reliable data on paternal age. ${ }^{18-}$ ${ }^{20}$ Thus, the potential association between advanced 
paternal age and health of the mother and offspring remains poorly defined. We examined the association of paternal age on maternal and neonatal health and estimated the impact of advancing paternal age in the US.

\section{Methods}

Data source

In this retrospective cohort analysis, we drew on data published by the National Vital Statistics System, a federal data sharing programme provided by the Centers for Disease Control and Prevention and the National Center for Health Statistics. Through contracts with individual vital registration systems within each state, the National Center for Health Statistics compiles data on live births from birth certificates and permits distribution of these statistics for medical research purposes. Standard birth certificates contain self reported parental demographics such as age, race, and education as well as pregnancy and birth outcomes, which are documented by healthcare providers. All births occurring within the US since 1985 are captured by this system. ${ }^{21}$ The National Center for Health Statistics provides training modules and guidelines for healthcare practitioners collecting birth data to ensure completion, accuracy, and standardization for reporting of vital events. ${ }^{22}$ Coding of the data also undergoes rigorous statistical quality checks and is edited for accuracy by the National Center for Health Statistics. If systematic reporting failures are noted, records are returned to the registration site for correction. ${ }^{20}$

\section{Study cohort and demographic variables}

In our analysis, we included all reported live births between 2007 and 2016 within the US. We compiled data files sequentially by year and extracted all available demographic variables, including age, race, education, marital status, smoking history, and access to care. Paternal age was categorized into 10 year intervals: $<25,25-34,35-44,45-54$, and 55 or older. ${ }^{23}$ Five year intervals were also analyzed, though no significant difference in trends were noted (see supplemental table 1). Racial categories were defined by the US Office of Management and Budget, and we categorized participants on the basis of how they self identified. Data on paternal education were unavailable until 2009 owing to the collection policy of the National Center for Health Statistics. We used inverse probability weighting to account for missing paternal data from birth certificates. ${ }^{24}$ To account for inconsistent reporting of paternal data across various demographics, we utilized a logistic regression model incorporating maternal age, race, birth year, and education to model the probability of paternal reporting for each birth. Inverse probability weighting was subsequently applied to all statistical analyses to maximize generalizability to all births. This weighting methodology has been described previously. ${ }^{24}$

\section{Outcomes}

The primary outcome of interest was the perinatal risk to child and mother correlated with advanced paternal age. We conducted a preliminary literature search to determine birth outcomes that have previously been associated with advanced paternal ages. Of these variables, we subsequently included those available within the National Vital Statistics System data files. Neonatal outcomes evaluated were premature birth (gestational age $<37$ weeks), low birth weight $(<2500 \mathrm{~g})$, low five minute Apgar score $(<8)$, assisted ventilation at birth, admission to the neonatal intensive care unit, requirement for postpartum antibiotics, and seizures. ${ }^{25}{ }^{26}$ We defined a neonatal adverse event as the requirement or occurrence of at least one of: assisted ventilation, admission to the neonatal intensive care unit, antibiotics, or seizure. The maternal outcomes evaluated were gestational diabetes, pre-eclampsia, and eclampsia. All variables were categorized as dichotomous, with gestational age, birth weight, and Apgar score also presented as continuous variables. For each paternal age group, we also evaluated the sex ratio of all births.

\section{Statistical analysis}

We analyzed mean paternal age with standard deviations along with standard demographics of all live births from 2007 and 2016 as a pooled cohort. To estimate the adjusted odds ratio for each perinatal outcome by paternal age group, we created logistic regression models with fathers aged 25 to 34 years as the reference group. Given the collinearity between paternal and maternal age, we also carried out stratified analyses based on maternal age and sensitivity analyses. Moreover, given the association between adverse birth outcomes and prematurity, we conducted separate analyses with only full term infants (see supplemental table 2). Other subgroup analyses were done to ensure that the paternal age association was not confounded by paternal age grouping, birth order, birth year, or missing paternal data (see supplemental tables). To test for a systematic change in sex ratio between paternal age groups, we compared the number and percentage of male and female births to each paternal age group. We used the Wilcoxon rank-sum test to determine statistically significant differences among age groups. A regression analysis was also conducted for each paternal age group to determine adjusted odds ratios of having a son.

The number and percentage of men who fathered children with each morbidity were compared. We also estimated the number of preventable perinatal events if fathers within the US were all younger than 45 years. The population attributable risk was calculated using the standard formula (observed prevalence-predicted prevalence of outcome after shift to new distribution of younger fathers)/(observed prevalence). ${ }^{27}{ }^{28}$ All statistical analysis was carried out using Stata version 14 (College Station, TX) and the user written package punaf (population attributable risk fraction). ${ }^{29}$ Statistical tests were two sided and 99 per cent 
confidence intervals were provided for precision of the estimates.

\section{Patient and public involvement}

The public was not involved in the development of the research question, formation of the study design, analysis of data, or interpretation of results. There are no plans to directly disseminate the study results to the study participants or wider patient communities.

\section{Results}

A total of 40529905 live births between 2007 and 2016 in the United States were evaluated. Table 1 shows paternal, maternal, and infant characteristics. The mean age of fathers during this period increased from 30.0 years to 31.2 years.

After adjustment for maternal age, race, education, smoking status, and number of prenatal visits, births related to the oldest fathers were associated with

\begin{tabular}{|c|c|c|c|c|c|c|}
\hline \multirow[b]{2}{*}{ Characteristics } & \multicolumn{5}{|l|}{ Paternal age (years) } & \multirow[b]{2}{*}{ Missing paternal age } \\
\hline & $<25$ & $25-34$ & $35-44$ & $45-54$ & $\geq 55$ & \\
\hline Birth certificates & $6319860(15.6)$ & $18289776(45.1)$ & $8476310(20.9)$ & $1091848(2.7)$ & $111130(0.3)$ & 6240981 \\
\hline \multicolumn{7}{|l|}{ Paternal characteristics } \\
\hline \multicolumn{7}{|l|}{ Race: } \\
\hline White & $2675449(42.3)$ & $10514234(57.5)$ & $4813626(56.8)$ & $547388(50.1)$ & $51299(46.2)$ & $548536(8.8)$ \\
\hline Black & $1173282(18.6)$ & $2004854(11.0)$ & $957685(11.3)$ & $197292(18.1)$ & $25535(23.0)$ & $179190(2.9)$ \\
\hline Native American & $84260(1.3)$ & $129771(0.7)$ & $44769(0.5)$ & $6923(0.6)$ & $847(0.8)$ & $13005(0.2)$ \\
\hline Asian & $86488(1.4)$ & $961160(5.3)$ & $747699(8.8)$ & $83329(7.6)$ & $8062(7.3)$ & $74281(1.2)$ \\
\hline Hispanic & $2046130(32.4)$ & $4178787(22.9)$ & $1667539(19.7)$ & $215563(19.7)$ & 20141 (18.1) & $244879(3.9)$ \\
\hline Other or unknown & $254251(4.0)$ & $500970(2.7)$ & $244992(2.9)$ & $41353(3.8)$ & $5246(4.7)$ & $5181090(83.0)$ \\
\hline \multicolumn{7}{|l|}{ Education: } \\
\hline No high school & $1163624(18.4)$ & $1792661(9.8)$ & $720306(8.5)$ & $115949(10.6)$ & $13986(12.6)$ & $22930(0.4)$ \\
\hline High school & $2897740(45.9)$ & $7152708(39.1)$ & $2693506(31.8)$ & $370827(34.0)$ & $36582(32.9)$ & $48896(0.8)$ \\
\hline College & $105916(1.7)$ & $3898117(21.3)$ & $2555614(30.2)$ & $281475(25.8)$ & $28387(25.5)$ & $5657(0.1)$ \\
\hline Unknown & $2152580(34.1)$ & $5446290(29.8)$ & $2506884(29.6)$ & $323597(29.6)$ & $32175(29.0)$ & $6163498(98.8)$ \\
\hline \multicolumn{7}{|l|}{ Maternal characteristics } \\
\hline \multicolumn{7}{|l|}{ Age (years): } \\
\hline$<20$ & $5475967(86.7)$ & $3621663(19.8)$ & $324652(3.8)$ & $42161(3.9)$ & $5478(4.9)$ & $3211653(51.5)$ \\
\hline $20-29$ & $808886(12.8)$ & $13646776(74.6)$ & $4407694(52.0)$ & $382294(35.0)$ & 41164 (37.0) & $2447035(39.2)$ \\
\hline $30-39$ & $34765(0.5)$ & $1017567(5.6)$ & 3720600 (43.9) & $629762(57.7)$ & $58389(52.5)$ & $572413(9.2)$ \\
\hline$\geq 40$ & $242(0.0)$ & $3770(0.0)$ & $23364(0.3)$ & $37631(3.5)$ & $6099(5.5)$ & $9880(0.2)$ \\
\hline \multicolumn{7}{|l|}{ Race: } \\
\hline White & $2947988(46.7)$ & $10918297(59.7)$ & $4915885(58.0)$ & $541681(49.6)$ & $45072(40.6)$ & $2407096(38.6)$ \\
\hline Black & $1038967(16.4)$ & $1753821(9.6)$ & $846975(10.0)$ & $176350(16.2)$ & $23795(21.4)$ & $2074983(33.2)$ \\
\hline Native American & $89035(1.4)$ & $135352(0.7)$ & $45390(0.5)$ & $7022(0.6)$ & $816(0.7)$ & $99588(1.6)$ \\
\hline Asian & $131870(2.1)$ & $1178655(6.4)$ & $918320(10.8)$ & $130083(11.9)$ & 18104 (16.3) & $180402(2.9)$ \\
\hline Hispanic & $2041846(32.3)$ & $4185812(22.9)$ & $1704974(20.1)$ & $230456(21.1)$ & $22685(20.4)$ & $1417190(22.7)$ \\
\hline Other or unknown & $70154(1.1)$ & $117839(0.6)$ & $44766(0.5)$ & $6256(0.6)$ & $658(0.6)$ & $61722(1.0)$ \\
\hline \multicolumn{7}{|l|}{ Education: } \\
\hline Less than high school & $1615314(25.6)$ & $2142333(11.7)$ & 888685 (10.5) & $157039(14.4)$ & $19876(17.9)$ & $1571612(25.2)$ \\
\hline High school & $3974943(62.9)$ & $8863877(48.5)$ & $3222251(38.0)$ & $455578(41.7)$ & $48311(43.5)$ & $2895458(46.4)$ \\
\hline College & $226784(3.6)$ & $5843718(32.0)$ & $3666236(43.3)$ & $384519(35.2)$ & $33158(29.8)$ & $216967(3.5)$ \\
\hline Unknown & $502819(8.0)$ & $1439848(7.9)$ & $699138(8.3)$ & $94712(8.7)$ & $9785(8.8)$ & $1556944(24.9)$ \\
\hline \multicolumn{7}{|l|}{ Median (interquartile range) } \\
\hline No of prenatal visits* & $11(9-13)$ & $12(10-13)$ & $12(10-14)$ & $12(9-14)$ & $11(9-13)$ & $10(8-13)$ \\
\hline Married & $2108222(33.4)$ & $13229565(72.3)$ & $6958644(82.2)$ & $835087(76.5)$ & $80465(72.4)$ & $936607(15.0)$ \\
\hline Gestational diabetes & $185717(2.9)$ & $967204(5.3)$ & $661093(7.8)$ & $104321(9.6)$ & $10746(9.7)$ & $283818(4.5)$ \\
\hline Pre-eclampsia & $297358(4.7)$ & $832200(4.6)$ & $385532(4.6)$ & $54894(5.0)$ & $5769(5.2)$ & 307963 (4.9) \\
\hline Eclampsia & $16938(0.3)$ & $40641(0.2)$ & $20029(0.2)$ & $3041(0.3)$ & $330(0.3)$ & $21107(0.3)$ \\
\hline \multicolumn{7}{|l|}{ Infant characteristics } \\
\hline Mean $\left(99 \% \mathrm{Cl}\right.$ ) birth weight $(\mathrm{g})^{\star}$ & $\begin{array}{l}3220 \\
\text { (3219.4 to 3220.6) }\end{array}$ & $\begin{array}{l}3306.6 \\
\text { (3306.3 to } 3306.9 \text { ) }\end{array}$ & $\begin{array}{l}3304.6 \\
\text { (3304.1 to } 3305.2 \text { ) }\end{array}$ & $\begin{array}{l}3253.2 \\
\text { (3251.6 to } 3254.8 \text { ) }\end{array}$ & $\begin{array}{l}3202.4 \\
\text { (3197.4 to } 3207.4)\end{array}$ & $\begin{array}{l}3148.4 \\
\text { (3147.7 to } 3149.0)\end{array}$ \\
\hline $\begin{array}{l}\text { Mean }(99 \% \mathrm{Cl}) \text { gestational age } \\
(\text { weeks)* }\end{array}$ & $\begin{array}{l}38.69 \\
\text { (38.68 to 38.69) }\end{array}$ & $\begin{array}{l}38.72 \\
\text { (38.72 to } 38.72 \text { ) }\end{array}$ & $\begin{array}{l}38.54 \\
\text { (38.54 to 38.54) }\end{array}$ & $\begin{array}{l}38.36 \\
\text { (38.35 to } 38.37 \text { ) }\end{array}$ & $\begin{array}{l}38.26 \\
\text { (38.24 to } 38.28)\end{array}$ & $\begin{array}{l}38.35 \\
\text { (38.35 to 38.36) }\end{array}$ \\
\hline $\begin{array}{l}\text { Premature birth } \\
\text { (<37 weeks) }\end{array}$ & $745615(11.8)$ & $1902785(10.4)$ & $993011(11.7)$ & $154819(14.2)$ & $17867(16.1)$ & $959100(15.4)$ \\
\hline $\begin{array}{l}\text { Low birth weight } \\
(<2500 \mathrm{~g})\end{array}$ & $518957(8.2)$ & $1273508(7.0)$ & $663742(7.8)$ & $107612(9.9)$ & $13031(11.7)$ & $704080(11.3)$ \\
\hline Low 5 minute Apgar score $(<8)$ & $258283(4.1)$ & $617300(3.4)$ & $281172(3.3)$ & 42269 (3.9) & $4928(4.4)$ & $295878(4.7)$ \\
\hline Assisted ventilation & $200197(3.2)$ & $547699(3.0)$ & $259905(3.7)$ & $37986(3.5)$ & $4178(3.8)$ & $193697(3.1)$ \\
\hline Admission to NICU & $385777(6.1)$ & $1095543(6.0)$ & $563784(6.7)$ & $89329(8.2)$ & $10648(9.6)$ & $424343(6.8)$ \\
\hline Postpartum antibiotics & $116124(1.8)$ & $302290(1.7)$ & $134836(1.6)$ & $19865(1.8)$ & $2,235(2.0)$ & $114295(1.8)$ \\
\hline Seizures & $1715(0.0)$ & $4409(0.0)$ & $2000(0.0)$ & $300(0.0)$ & $33(0.0)$ & $1986(0.0)$ \\
\hline Adverse event & $524725(8.3)$ & $1449012(7.9)$ & $720770(8.5)$ & $110645(10.1)$ & $12833(11.6)$ & $543107(8.7)$ \\
\hline
\end{tabular}

$\mathrm{NICU}=$ neonatal intensive care unit.

Missing paternal age data are presented as number of birth certificates without paternal age for each category and percentage of total number of missing paternal age data. 


\begin{tabular}{|c|c|c|c|c|c|}
\hline \multirow[b]{2}{*}{ Birth outcomes } & \multicolumn{5}{|l|}{ Paternal age (years) } \\
\hline & $<25$ & $25-34$ & $35-44$ & 45-54 & $\geq 55$ \\
\hline \multicolumn{6}{|c|}{ Gestational age coefficient (weeks): } \\
\hline Unadjusted & $-0.03(-0.04$ to -0.03$)$ & Reference & $-0.18(-0.18$ to -0.18$)$ & $-0.36(-0.37$ to -0.35$)$ & $-0.46(-0.48$ to -0.44$)$ \\
\hline Adjusted & $-0.01(-0.02$ to -0.01$)$ & Reference & $-0.06(-0.07$ to -0.06$)$ & $-0.12(-0.13$ to -0.11$)$ & $-0.17(-0.20$ to -0.14$)$ \\
\hline \multicolumn{6}{|c|}{ Birth weight coefficient (g): } \\
\hline Unadjusted & $-86.6(-87.3$ to -85.9$)$ & Reference & $-1.97(-2.59$ to -1.34$)$ & $-53.4(-54.9$ to -51.9$)$ & $-104.2(-108.7$ to -99.7$)$ \\
\hline Adjusted & $-22.9(-24.1$ to -21.7$)$ & Reference & $0.95(-0.02$ to 1.91$)$ & $-20.2(-22.5$ to -18.0$)$ & $-49.2(-55.9$ to -42.5$)$ \\
\hline \multicolumn{6}{|c|}{ Apgar coefficient (5 min): } \\
\hline Unadjusted & $-0.03(-0.04$ to -0.03$)$ & Reference & $0.01(0.00$ to 0.01$)$ & $-0.02(-0.03$ to -0.02$)$ & $-0.05(-0.06$ to -0.05$)$ \\
\hline Adjusted & $-0.02(-0.02$ to -0.02$)$ & Reference & $0.01(0.01$ to 0.01$)$ & $-0.01(-0.01$ to -0.01$)$ & $-0.02(-0.03$ to -0.01$)$ \\
\hline \multicolumn{6}{|c|}{ Premature birth ( $<37$ weeks): } \\
\hline Unadjusted & 1.15 (1.15 to 1.16$)$ & Reference & $1.14(1.14$ to 1.15$)$ & $1.42(1.41$ to 1.43$)$ & 1.65 (1.62 to 1.69$)$ \\
\hline Adjusted & $1.03(1.02$ to 1.04$)$ & Reference & $1.06(1.05$ to 1.06$)$ & $1.14(1.13$ to 1.15$)$ & $1.25(1.22$ to 1.29$)$ \\
\hline \multicolumn{6}{|c|}{ Low birth weight $(<2500 \mathrm{~g})$ : } \\
\hline Unadjusted & $1.20(1.19$ to 1.20$)$ & Reference & 1.14 (1.13 to 1.14$)$ & $1.46(1.45$ to 1.47$)$ & $1.78(1.73$ to 1.82$)$ \\
\hline Adjusted & $1.05(1.04$ to 1.06$)$ & Reference & $1.04(1.04$ to 1.05$)$ & $1.14(1.12$ to 1.15$)$ & $1.27(1.22$ to 1.31$)$ \\
\hline \multicolumn{6}{|c|}{ Low 5 minute Apgar score $(<8)$ : } \\
\hline Unadjusted & $1.23(1.23$ to 1.24$)$ & Reference & $0.98(0.97$ to 0.98$)$ & 1.15 (1.14 to 1.17$)$ & $1.34(1.29$ to 1.39$)$ \\
\hline Adjusted & $1.11(1.10$ to 1.12$)$ & Reference & 0.97 (0.96 to 0.98) & $1.04(1.02$ to 1.06$)$ & 1.14 (1.08 to 1.20$)$ \\
\hline \multicolumn{6}{|c|}{ Assisted ventilation: } \\
\hline Unadjusted & $1.06(1.05$ to 1.07$)$ & Reference & $1.02(1.02$ to 1.03$)$ & 1.17 (1.15 to 1.18$)$ & $1.27(1.21$ to 1.32$)$ \\
\hline Adjusted & $1.04(1.02$ to 1.05$)$ & Reference & $1.00(0.99$ to 1.01$)$ & $1.06(1.04$ to 1.16$)$ & $1.10(1.04$ to 1.16$)$ \\
\hline \multicolumn{6}{|c|}{ Admission to NICU: } \\
\hline Unadjusted & $1.03(1.03$ to 1.04$)$ & Reference & 1.12 (1.11 to 1.12$)$ & 1.39 (1.38 to 1.40$)$ & 1.64 (1.59 to 1.68$)$ \\
\hline Adjusted & 1.01 (1.00 to 1.02$)$ & Reference & 1.03 (1.03 to 1.04$)$ & $1.14(1.13$ to 1.16$)$ & 1.28 (1.24 to 1.33$)$ \\
\hline \multicolumn{6}{|c|}{ Postpartum antibiotics: } \\
\hline Unadjusted & $1.13(1.12$ to 1.14$)$ & Reference & $0.96(0.95$ to 0.97$)$ & $1.09(1.07$ to 1.11$)$ & $1.20(1.13$ to 1.26$)$ \\
\hline Adjusted & 1.04 (1.03 to 1.06$)$ & Reference & $0.96(0.95$ to 0.97$)$ & $1.03(1.00$ to 1.05$)$ & $1.06(0.99$ to 1.14$)$ \\
\hline \multicolumn{6}{|l|}{ Seizures: } \\
\hline Unadjusted & 1.14 (1.06 to 1.22$)$ & Reference & 0.98 (0.91 to 1.05$)$ & 1.13 (0.97 to 1.32$)$ & 1.21 (0.77 to 1.89$)$ \\
\hline Adjusted & $1.06(0.93$ to 1.20$)$ & Reference & $1.00(0.91$ to 1.11$)$ & $1.18(0.97$ to 1.44$)$ & $1.30(0.77$ to 2.20$)$ \\
\hline \multicolumn{6}{|l|}{ Adverse event*: } \\
\hline Unadjusted & 1.05 (1.05 to 1.06$)$ & Reference & 1.08 (1.07 to 1.08$)$ & 1.31 (1.30 to 1.32$)$ & 1.52 (1.48 to 1.55$)$ \\
\hline Adjusted & $1.03(1.02$ to 1.03$)$ & Reference & $1.02(1.01$ to 1.02$)$ & $1.12(1.11$ to 1.13$)$ & $1.24(1.20$ to 1.28$)$ \\
\hline \multicolumn{6}{|c|}{ Gestational diabetes: } \\
\hline Unadjusted & $0.83(0.82$ to 0.83$)$ & Reference & 1.15 (1.15 to 1.16$)$ & 1.28 (1.27 to 1.29$)$ & 1.34 (1.30 to 1.38$)$ \\
\hline Adjusted & $0.82(0.81$ to 0.83$)$ & Reference & $1.16(1.15$ to 1.16$)$ & 1.28 (1.27 to 1.30$)$ & 1.34 (1.29 to 1.38$)$ \\
\hline \multicolumn{6}{|l|}{ Pre-eclampsia: } \\
\hline Unadjusted & 1.04 (1.03 to 1.04$)$ & Reference & $1.00(0.99$ to 1.00$)$ & 1.11 (1.10 to 1.12$)$ & 1.15 (1.11 to 1.19$)$ \\
\hline Adjusted & $1.06(1.05$ to 1.07$)$ & Reference & 0.97 (0.96 to 0.97) & $0.99(0.98$ to 1.01$)$ & $1.00(0.96$ to 1.05$)$ \\
\hline \multicolumn{6}{|l|}{ Eclampsia: } \\
\hline Unadjusted & $1.21(1.18$ to 1.24$)$ & Reference & 1.06 (1.04 to 1.09$)$ & 1.25 (1.20 to 1.32$)$ & $1.34(1.16$ to 1.54$)$ \\
\hline Adjusted & 1.11 (1.06 to 1.16$)$ & Reference & $0.99(0.96$ to 1.03$)$ & $1.02(0.95$ to 1.10$)$ & $1.03(0.84$ to 1.25$)$ \\
\hline
\end{tabular}

$\mathrm{NICU}=$ neontatal intensive care unit.

*Required assisted ventilation, admission to a NICU, postpartum antibiotics, or had seizure after bith.

worse outcomes (table 2). Gestational ages were lower in children born to fathers aged more than 45 years (on average 0.12 weeks younger, 99\% confidence interval -0.13 to -0.11 weeks) and had $14 \%$ higher odds of having a premature birth $(<37$ weeks) compared with younger fathers (adjusted odds ratio 1.14 , 99\% confidence interval 1.13 to 1.15). Infants born to fathers aged 45-54 years were also born 20.2 g lighter (99\% confidence interval -22.5 to -18.0 and had a $14 \%$ greater risk of low birth weight $(<2500 \mathrm{~g})$ than infants born to younger fathers (adjusted odds ratio 1.14, 99\% confidence interval 1.12 to 1.15). The odds of having a low Apgar score $(<8)$ was greater for fathers aged 55 years or older (1.14, 1.08 to 1.20$)$.
Infants born to fathers aged 55 years or older also had a significantly higher risk of requiring additional medical care after birth. The odds of the infant requiring assisted ventilation increased by $10 \%$ (adjusted odds ratio 1.10, 99\% confidence interval 1.04 to 1.16 ) and the odds of requiring admission to the neonatal intensive care unit increased by $28 \%$ $(1.28,1.24$ to 1.33$)$.

The secondary sex ratio declined with increasing paternal age (table 3$)$. Younger fathers ( $<25$ years) were more likely to have a boy than fathers aged 25-34 years after adjustment for other paternal and maternal characteristics, including maternal age (adjusted odds ratio 1.01 , 99\% confidence interval 1.00 to 1.01 ). However, no change in the secondary sex ratio was 


\begin{tabular}{|c|c|c|c|c|c|}
\hline \multirow[b]{2}{*}{ Variables } & \multicolumn{5}{|l|}{ Paternal age (years) } \\
\hline & $<25$ & $25-34$ & $35-44$ & $45-54$ & $\geq 55$ \\
\hline No (\%) women & $4134050(48.7)$ & $10351338(48.8)$ & $4612303(48.8)$ & $603896(48.9)$ & $60795(48.8)$ \\
\hline No (\%) men & $4361018(51.3)$ & $10870121(51.2)$ & $4835218(51.2)$ & $632267(51.1)$ & $64848(51.2)$ \\
\hline Odds ratio $(99 \% \mathrm{Cl})$ & $1.01(1.00$ to 1.01$)$ & Reference & 1.00 (0.99 to 1.00$)$ & 1.00 (0.99 to 1.00$)$ & 1.00 (0.99 to 1.02$)$ \\
\hline
\end{tabular}

noted for fathers aged 45-54 years (1.00, 0.99 to 1.00). A subanalysis was additionally conducted excluding births that resulted from in vitro fertilization $(1.53 \%$ of all births), with no changes to the conclusions.

Pregnancy related outcomes for mothers were also examined. Fathers older than 45 years had a $28 \%$ increased odds of a pregnancy complicated by gestational diabetes compared with fathers in the reference group $(1.28,1.27$ to 1.30$)$, though no significant association was found between paternal age and risk of pre-eclampsia or eclampsia $(0.99,0.98$ to 1.01 and 1.02, 0.95 to 1.10 , respectively).

After stratification by maternal age, increasing paternal age remained significantly associated with

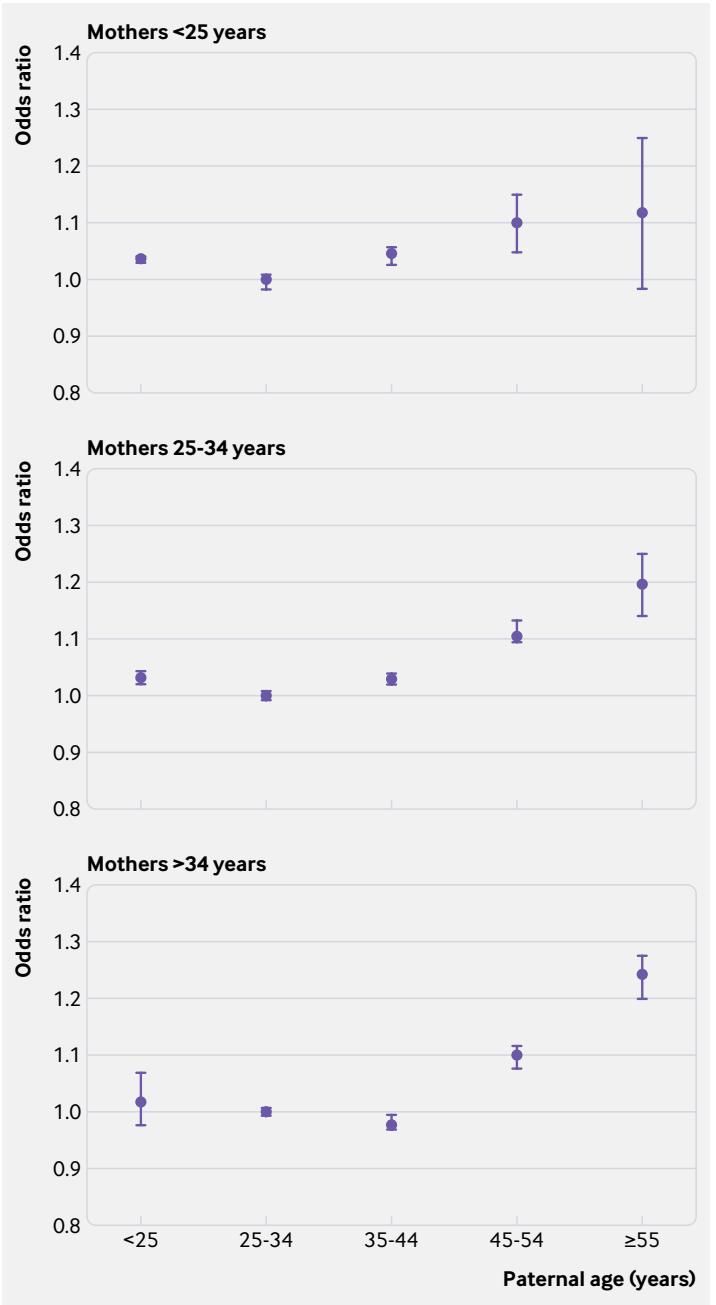

Fig 1 | Scatter plots of odds of an adverse birth event by paternal age stratified by maternal age group. Error bars indicate $99 \%$ confidence intervals based on distribution of births within each paternal age group perinatal outcomes, with similar trends across all stratums for maternal age (fig 1 and supplemental fig 1). Similar findings were noted when the analysis was limited to first births for mothers (see supplemental table 3). In addition, similar findings were identified during separate periods (2007 v 2016) indicating that these trends were not influenced by recent changes in medical practice (see supplemental table 4).

To estimate the population attributable risk of advanced paternal age, we recalculated the distribution of paternal age groups for a scenario in which all fathers were younger than 45 years. Table 4 shows that over the past decade $13.2 \%$ (95\% confidence interval $12.5 \%$ to $13.9 \%$ ) of premature births and $14.5 \%$ (13.6\% to $15.4 \%)$ of low birth weight infants with older fathers (under the assumption of a causal relation) can be attributed to the increase in number of fathers older than 45 years. Further, 15.1\% (14.2\% to $15.9 \%$ ) of admissions to a neonatal intensive care unit and $18.2 \%$ (17.5\% to $18.9 \%)$ of gestational diabetes diagnoses were also attributable to these older fathers.

\section{Discussion}

Paternal age is increasing in the United States with potential implications for maternal and child health. Infants born to fathers aged more than 35 years were found to be at a higher risk of premature birth, low birth weight, and increased morbidity (eg, assisted ventilation, stay in a neonatal intensive care unit, postpartum antibiotics) during the perinatal period. A large percentage of cases of premature births, low birth weight, and admissions to a neonatal intensive care unit in children of older fathers was found to be associated with advanced paternal age. In addition, increased paternal age was negatively associated with maternal health as identified through an inceased risk of gestational diabetes. Though, as the prevalence of advanced paternal age was modest, the impact of these associations at a population level remains uncertain. Indeed, the increased odds ratios were $<1.5$, suggesting the overall risk of these outcomes likely still remains low. The increased risks associated with father's age appeared to be dose dependent, with a J-shaped association curve. While the youngest fathers tended to have worse perinatal outcomes than men in their 20s, fathers aged 45 years or older seemed to have significantly worse outcomes. This trend continued with increasing age (dose).

\section{Comparison with other studies}

Theinitialidentification of paternal contribution to birth outcome dates back to Wilhelm Weinberg's discovery in 1912 of a correlation between achondroplasia and 


\begin{tabular}{|c|c|c|c|c|c|}
\hline \multirow[b]{2}{*}{ Perinatal outcomes } & \multirow[b]{2}{*}{ Total No of cases } & \multicolumn{2}{|c|}{ Paternal age (years) } & \multirow[b]{2}{*}{ P value } & \multirow[b]{2}{*}{$\%$ of cases prevented if paternal age was $<45(95 \% \mathrm{Cl})$} \\
\hline & & $<45$ & $\geq 45$ & & \\
\hline Premature birth ( $<37$ weeks) & 4608250 & $4409654(11.3)$ & $198597(14.6)$ & $<0.001$ & $13.2(12.5$ to 13.9$)$ \\
\hline Low birth weight (<2500 g) & 3141068 & $3003266(7.7)$ & $137802(10.1)$ & $<0.001$ & $14.5(13.6$ to 15.4$)$ \\
\hline Low 5 minute Apgar score $(<8)$ & 1629302 & $1568507(4.0)$ & $60795(4.5)$ & $<0.001$ & $5.9(4.5$ to 7.2$)$ \\
\hline Gestational diabetes & 2225092 & $2095396(5.3)$ & $129696(9.5)$ & $<0.001$ & $18.2(17.5$ to 18.9$)$ \\
\hline Pre-eclampsia & 1876535 & $1807634(4.6)$ & $68901(5.1)$ & $<0.001$ & $3.9(2.8$ to 5.0$)$ \\
\hline Eclampsia & 97069 & $93219(0.2)$ & $3850(0.3)$ & $<0.001$ & 5.4 (0.1 to 11.0$)$ \\
\hline Assisted ventilation & 1483395 & $1426653(3.6)$ & $56742(4.2)$ & $<0.001$ & $8.6(7.2$ to 9.9$)$ \\
\hline Admission to NICU & 3035690 & $2901941(7.4)$ & $133749(9.8)$ & $<0.001$ & 15.1 (14.2 to 15.9$)$ \\
\hline Postpartum antibiotics & 816272 & $786280(2.0)$ & $29992(2.2)$ & $<0.001$ & $6.2(4.4$ to 8.0$)$ \\
\hline Seizures & 11794 & $11348(0.0)$ & $446(0.0)$ & 0.04 & 19.9 (2.9 to 36.7$)$ \\
\hline Adverse event & 3351823 & $3209968(8.2)$ & $141855(10.4)$ & $<0.001$ & $12.2(11.5$ to 13.0$)$ \\
\hline
\end{tabular}

birth order, but it was James Crow's seminal work at the turn of the century that spurred major interest into paternal age effects on infant health. ${ }^{9}{ }^{30}$ Still, there is a dearth of published data on the paternal effects on birth outcomes, and the little existing data have been mostly equivocal. Studies evaluating the association between paternal age and risk of pre-eclampsia, low Apgar scores, and admission to a neonatal intensive care unit have also been rare.

One study evaluated 1.5 million births in Italy between 1990 and 1998 and observed that fathers aged 45 to 49 had a higher risk of severely preterm births ( $<32$ weeks of gestation) compared with fathers aged 25 to 29 , particularly in firstborn children. ${ }^{19}$ In contrast, a study of 2.5 million births in the US to nulliparous women between 1995 and 2000 found an association between teenage fathers and preterm births but no association for fathers with advanced age. ${ }^{20}$ In this study, however, only $0.5 \%$ of births (13907 total births) were to fathers aged more than 45. The risk of other perinatal complications, such as pre-eclampsia, low birth weight, and low Apgar scores also remains uncertain given mixed findings from mostly underpowered studies. ${ }^{1} 18252631-38$ While a study initially found that fathers older than 35 years were at increased risk of low birthweight offspring, the findings were later questioned owing to missing paternal ages thought to result in selection bias. ${ }^{20} 33$ Moreover, another study examined more than one million births in Ohio from 2006 to 2012 and did not identify associations between paternal age and preeclampsia, preterm birth, fetal growth restriction, congenital anomaly, genetic disorder, or admission to a neonatal intensive care unit. ${ }^{39}$

Recent studies have begun to uncover a potential epigenetic link between the aging paternal genome and health outcomes in offspring. ${ }^{40}$ Age dependent alterations, such as DNA methylation, have been observed in mammalian somatic and germline cells. Higher rates of methylation were found on ribosomal DNA of older rat spermatozoa compared with younger controls. ${ }^{41}$ Additionally, genomic imprinting has been suggested to influence placental growth, morphology, and nutrient transfer, which in part explains the paternal influence on birth outcomes. ${ }^{42}$ For example, the overexpression of a demethylase enzyme (Kdm1a) in mice was found to result in loss of methylation of H3K4, an epigenetic marker associated with developmental genes in sperm. The offspring of these mice had increased rates of birth defects and neonatal mortality. ${ }^{43} 44$ Similarly, interferon-like growth factor 2 is a paternally expressed gene susceptible to epigenetic modification that affects growth factors for both the placenta and the embryo. ${ }^{16} 17$ This could partially explain the increased placental weight found in pregnancies to older fathers, which in turn has been associated with an increased risk for pre-eclampsia and other maternal comorbidities (eg, gestational diabetes). ${ }^{45}$ It has become increasingly clear that male aging influences germline integrity through other mechanisms as well, such as DNA fragmentation, telomere lengthening, mutations, and overall genomic instability. ${ }^{23}$ Investigators have estimated that males develop approximately two additional mutations in their germline DNA throughout life, with de novo mutations increasing the risk of preterm birth. ${ }^{1146}$ In addition, pre-eclampsia and epilepsy have also been associated with paternal age. ${ }^{32} 47$ A need exists to further elucidate the potential causal relation between advanced paternal age and maternal and infant outcomes, though it seems that the paternal effect on placental health may play a non-trivial, though speculative role.

\section{Strengths and limitations of this study}

The current study incorporates all live births over a span of 10 years, allowing for an unbiased analysis of recent trends. The pooling of all births during this period minimizes the risk of confounding from yearly fluctuations in perinatal outcomes. Moreover, similar measures of association were identified from separate periods within the cohort, indicating that findings do not reflect a time dependent phenomenon. Given the increased risk of negative birth outcomes in premature births, a subset analysis with only term births was conducted to corroborate the paternal age findings. The addition of inverse probability weighting further reduces the overrepresentation of 
certain demographics of fathers: mostly older, college educated fathers who are more likely to be present at birth. ${ }^{2}$ Other advantages of utilizing national birth certificate data provided by the National Center for Health Statistics are that this unique system allows for incorporation of important covariates as well as for the formulation of weighting to adjust for missing paternal data. The inclusion of all births within the US allows for estimation of rates of occurrence and associated attributable risk fractions, which facilitates evaluation of the public health impact of aging fathers. ${ }^{29}$

Though this study found an overall positiveassociation between older fathers and declining sex ratio, the oldest group still maintained a similar proportion of male compared with female offspring as the reference group. Thus, there seems to be no meaningful alteration in secondary sex ratio based on paternal age. It remains likely that an altered secondary sex ratio is due to a combination of genetics and environmental exposures, which are more likely to explain the declining ratio than advanced paternal age. ${ }^{48}$

The use of the Vital Statistics System for perinatal research has several limitations. The natality database uses birth certificate data that are completed by parents and healthcare workers and these are reviewed for errors but remain susceptible to inaccuracies. This database is also limited to live births, which prevents the inclusion of stillbirths in the analysis. However, as fetal mortality is known to be associated with advanced paternal age, the inclusion of these data would likely reinforce the findings of this study. ${ }^{49}$ Though inverse probability weighting was used to adjust for missing paternal data, the potential for overrepresentation of fathers from certain sociodemographic backgrounds remains. ${ }^{2}$ Multiple births to the same father are also not accounted for in this study as all data are collected at the maternal level, allowing for the potential bias of some at risk fathers disproportionately contributing to estimated effects. Finally, despite attempts to adjust and account for potential maternal confounding using regression analysis and stratification, some residual confounding effects from older fathers being associated with older mothers could remain.

\section{Conclusions and policy implications}

This study evaluated potential fetal-maternal risks associated with advanced paternal age. As more than $12 \%$ of births to fathers aged 45 years or older with adverse outcomes might have been prevented were the father younger, the importance of these data are most relevant to parents planning their reproductive future. Preconception counseling guidelines might need to change to incorporate the possibility that delaying parenthood for fathers might not be as inconsequential as previously understood. The cumulative risk over hundreds of thousands of births to older fathers is also likely to be important in terms of both economic burden and overall public health. While it is important to note that the absolute risk of advancing paternal age on adverse perinatal conditions remains modest, our findings emphasize the need to further investigate the public health implications of increasing paternal age within the US and other countries.

Contributors: All authors were involved in the design of the study, collection and analysis of the data, interpretation of the findings, and preparation and review of the manuscript. ME is the guarantor. The corresponding author attests that all listed authors meet authorship criteria and that no others meeting the criteria have been omitted. Funding: None.

Competing interests: All authors have completed the ICMJE uniform disclosure form at www.icmje.org/coi_disclosure.pdf and declare: no support from any organization for the submitted work; no financial relationships with any organisations that might have an interest in the submitted work in the previous three years; no other relationships or activities that could appear to have influenced the submitted work.

Ethical approval: Not required.

Data sharing: No additional data available.

Transparency: The lead author (ME) affirms that the manuscript is an honest, accurate, and transparent account of the study being reported; that no important aspects of the study have been omitted; and that any discrepancies from the study as planned (and, if relevant, registered) have been explained.

This is an Open Access article distributed in accordance with the Creative Commons Attribution Non Commercial (CC BY-NC 4.0) license, which permits others to distribute, remix, adapt, build upon this work non-commercially, and license their derivative works on different terms, provided the original work is properly cited and the use is noncommercial. See: http://creativecommons.org/licenses/by-nc/4.0/.

1 Hamilton BE, Martin JA, Osterman MJ, Curtin SC, Matthews TJ. Births: Final Data for 2014. Natl Vital Stat Rep 2015;64:1-64

Khandwala YS, Zhang CA, Lu Y, Eisenberg ML. The age of fathers in the USA is rising: an analysis of 168867480 births from 1972 to 2015. Hum Reprod 2017;32:2110-6. http://academic.oup.com/humrep/article/doi/10.1093/humrep/ dex267/4096427/The-age-of-fathers-in-the-USA-is-rising-an. doi:10.1093/humrep/dex267

3 Conti SL, Eisenberg ML. Paternal aging and increased risk of congenital disease, psychiatric disorders, and cancer. Asian J Androl 2016;18:420-4. www.ajandrology.com/text. asp?2016/18/3/420/175097. doi:10.4103/1008-682X.175097

4 Wiener-Megnazi Z, Auslender R, Dirnfeld M. Advanced paternal age and reproductive outcome. Asian J Androl 2012;14:69-76. www.pubmedcentral.nih.gov/articlerender. fcgi?artid=3735149\&tool=pmcentrez\&rendertype=abstract. doi:10.1038/aja.2011.69

5 Heffner LJ. Advanced maternal age--how old is too old? N EnglJ Med 2004:351:1927-9. http://search.ebscohost.com/login.aspx?di ect $=$ true \&db=c8h\&AN=106597637\&lang=es\&site=ehost-live.

6 Puleo CM, Schmeidler J, Reichenberg A, et al. Advancing paternal age and simplex autism. Autism 2012;16:367-80. doi:10.1177/1362361311427154

7 Croen LA, Najjar DV, Fireman B, Grether JK. Maternal and paternal age and risk of autism spectrum disorders. Arch Pediatr Adolesc Med 2007;161:334-40. http://archpedi.jamanetwork.com/article. aspx?doi=10.1001/archpedi.161.4.334\%5Cnhttp://booksc.org/ book/44396145. doi:10.1001/archpedi.161.4.334

8 Paulson RJ, Boostanfar R, Saadat P, et al. Pregnancy in the sixth decade of life: obstetric outcomes in women of advanced reproductive age. JAMA 2002;288:2320-3.

9 Crow JF. The origins, patterns and implications of human spontaneous mutation. Nat Rev Genet 2000;1:40-7. www.nature.com/doifinder/10.1038/35049558. doi:10.1038/35049558

10 Frans EM, Sandin S, Reichenberg A, Lichtenstein P, Långström N, Hultman CM. Advancing paternal age and bipolar disorder. Arch Gen Psychiatry 2008;65:1034-40. http://archpsyc. jamanetwork.com/article.aspx?doi=10.1001/archpsyc.65.9.1034 doi:10.1001/archpsyc.65.9.1034

11 Kong A, Frigge ML, Masson G, et al. Rate of de novo mutations and the importance of father's age to disease risk. Nature 2012;488:471-5. doi:10.1038/nature11396

12 Waller DK, Correa A, Vo TM, et al. The population-based prevalence of achondroplasia and thanatophoric dysplasia in selected regions of the US. Am J Med Genet A 2008;146A:2385-9. doi:10.1002/ajmg.a.32485

13 D'Onofrio BM, Rickert ME, Frans E, et al. Paternal age at childbearing and offspring psychiatric and academic morbidity. JAMA Psychiatry 2014;71:432-8. http://archpsyc.jamanetwork. com/article.aspx?doi=10.1001/jamapsychiatry.2013.4525. doi:10.1001/jamapsychiatry.2013.4525 
14 Sipos A, Rasmussen F, Harrison G, et al. Paternal age and schizophrenia: a population based cohort study. BMJ 2004;329:1070. www.bmj.com/cgi/doi/10.1136/ bmj.38243.672396.55. doi:10.1136/bmj.38243.672396.55

15 Jenkins TG, Aston KI, Pflueger C, Cairns BR, Carrell DT. Age-associated sperm DNA methylation alterations: possible implications in offspring disease susceptibility. PLoS Genet 2014;10:e1004458 doi:10.1371/journal.pgen.1004458

16 Miozzo M, Simoni G. The role of imprinted genes in fetal growth. Biol Neonate 2002;81:217-28. doi:10.1159/000056752

17 Parks JC, Tignanelli MD, McCubbin NI, McCallie BR, Schoolcraft WB, Katz-Jaffe M. Advanced paternal age directly impacts placental epigenetic mechanisms. Fertil Steril 2017;108:e24-5. doi:10.1016/j.fertnstert.2017.07.088

18 Nybo Andersen A-M, Urhoj SK. Is advanced paternal age a health risk for the offspring? Fertil Steril 2017;107:312-8. http://linkinghub.elsevier.com/retrieve/pii/S0015028216630911 doi:10.1016/j.fertnstert.2016.12.019

19 Astolfi P, De Pasquale A, Zonta LA. Paternal age and preterm birth in Italy, 1990 to 1998. Epidemiology 2006;17:218-21. doi:10.1097/01.ede.0000197053.61176.f4

20 Chen XK, Wen SW, Krewski D, Fleming N, Yang Q, Walker MC. Paternal age and adverse birth outcomes: teenager or $40+$, who is at risk? Hum Reprod 2008;23:1290-6. doi:10.1093/humrep/dem403

21 Schoendorf KC, Branum AM. The use of United States vital statistics in perinatal and obstetric research. Am / Obstet Gynecol 2006;194:911-5. doi:10.1016/j.ajog.2005.11.020

22 The Importance of Vital Records and Statistics for the Obstetrician-Gynecologist. The American College of Obstetricians and Gynecologists. 2015. www.acog.org/-/media/CommitteeOpinions/Committee-on-Health-Care-for-Underserved-Women/ c0639.pdf?dmc $=1 \& \mathrm{ts}=20160531 \mathrm{~T} 1358413757$

23 Sharma R, Agarwal A, Rohra VK, Assidi M, Abu-Elmagd M, Turki RF. Effects of increased paternal age on sperm quality, reproductive outcome and associated epigenetic risks to offspring. Reprod Biol Endocrinol 2015:13:35. doi:10.1186/s12958-015-0028-x

24 Mansournia MA, Altman DG. Inverse probability weighting. BMJ 2016;352:i189. doi:10.1136/bmj.i189

25 Sun Y, Vestergaard M, Zhu JL, Madsen KM, Olsen J. Paternal age and Apgar scores of newborn infants. Epidemiology 2006;17:473-4 doi:10.1097/01.ede.0000220690.43455.22

26 Shah PS, Knowledge Synthesis Group on determinants of preterm/low birthweight births. Paternal factors and low birthweight, preterm, and small for gestational age births: a systematic review. Am J Obstet Gynecol 2010;202:103-23. doi:10.1016/j.ajog.2009.08.026.

27 Benichou J. A review of adjusted estimators of attributable risk. Stat Methods Med Res 2001;10:195-216. doi:10.1177/096228020101000303

28 Maclnnis N, Woolcott CG, McDonald S, Kuhle S. Population Attributable Risk Fractions of Maternal Overweight and Obesity for Adverse Perinatal Outcomes. Sci Rep 2016;6:22895. doi:10.1038/srep22895.

29 Newson R. Attributable and unattributable risks and fractions and other scenario comparisons. Stata / 2013;13:672-98.

30 Crow JF. Development. There's something curious about paternal-age effects. Science 2003;301:606-7.

31 Alio AP, Salihu HM, McIntosh C, et al. The effect of paternal age on fetal birth outcomes. Am / Mens Health 2012;6:427-35. doi:10.1177/1557988312440718
32 Harlap S, Paltiel O, Deutsch L, et al. Paternal age and preeclampsia. Epidemiology 2002;13:660-7 doi:10.1097/00001648-200211000-00010

33 Reichman NE, Teitler JO. Paternal age as a risk factor for low birthweight. Am J Public Health 2006;96:862-6. doi:10.2105/AJPH.2005.066324

34 Tough SC, Faber AJ, Svenson LW, Johnston DW. Is paternal age associated with an increased risk of low birthweight, preterm delivery, and multiple birth? Can J Public Health 2003;94:88-92.

35 Zhu JL, Madsen KM, Vestergaard M, Basso O, Olsen J. Paternal age and preterm birth. Epidemiology 2005;16:259-62. doi:10.1097/01.ede.0000152526.63279.da

36 Parker JD, Schoendorf KC. Influence of paternal characteristics on the risk of low birth weight. Am J Epidemiol 1992;136:399-407. http:// aje.oxfordjournals.org/content/136/4/399.short\%5Cnpapers2:// publication/uuid/C012F2E6-9DE1-47A4-8EAB-0E9B53B1DE87. doi:10.1093/oxfordjournals.aje.a116512

37 Caughey AB, Cheng YW, Stotland NE, Washington AE, Escobar GJ. Maternal and paternal race/ethnicity are both associated with gestational diabetes. Am J Obstet Gynecol 2010;202:616.e1-5. doi:10.1016/j.ajog.2010.01.082

38 Kaveh M, Ghajarzadeh M, Tanha F, Savaheli S, Rezayof E.The Effect of Paternal Age on Preterm Births; a Survey of 281 Cases. J Fam Reprod Health 2012;6:125-9.

39 Hurley EG, DeFranco EA. Influence of paternal age on perinatal outcomes. Am J Obstet Gynecol 2017;217:566.e1-6. doi:10.1016/j.ajog.2017.07.034

40 Abbasi J. The paternal epigenome makes its mark. IAMA 2017:317:2049-51. doi:10.1001/jama.2017.1566

41 Oakes CC, Smiraglia DJ, Plass C, Trasler JM, Robaire B. Aging results in hypermethylation of ribosomal DNA in sperm and liver of male rats. Proc Natl Acad Sci U S A 2003;100:1775-80. www.pnas.org/cgi/ doi/10.1073/pnas.0437971100. doi:10.1073/pnas.0437971100

42 Miozzo M, Simoni G. The role of imprinted genes in fetal growth. Biol Neonate 2002;81:217-28. doi:10.1159/000056752

43 Yamauchi Y, Shaman JA, Ward WS. Non-genetic contributions of the sperm nucleus to embryonic development. Asian J Androl 2011;13:31-5. doi:10.1038/aja.2010.75

44 Siklenka K, Erkek S, Godmann M, et al. Disruption of histone methylation in developing sperm impairs offspring health transgenerationally. Science 2015;350:aab2006.

45 Strøm-Roum EM, Haavaldsen C, Tanbo TG, Eskild A. Paternal age, placental weight and placental to birthweight ratio: a population-based study of 590,835 pregnancies. Hum Reprod 2013;28:3126-33. doi:10.1093/humrep/det299

46 Li J, Oehlert J, Snyder M, Stevenson DK, Shaw GM. Fetal de novo mutations and preterm birth. PLoS Genet 2017;13:e1006689.

47 Vestergaard M, Mork A, Madsen KM, Olsen J. Paternal age and epilepsy in the offspring. Eur J Epidemiol 2005;20:1003-5. doi:10.1007/s10654-005-4250-2

48 Marcus M, Kiely J, Xu F, McGeehin M, Jackson R, Sinks T. Changing sex ratio in the United States, 1969-1995. Fertil Steril 1998;70:270-3. doi:10.1016/S0015-0282(98)00149-6

49 Nybo Andersen A-M, Hansen KD, Andersen PK, Davey Smith G. Advanced paternal age and risk of fetal death: a cohort study. Am J Epidemiol 2004:160:1214-22. doi:10.1093/aje/kwh332

Supplementary information: additional tables and figure 